\title{
Article \\ Numerical Assessment of an Innovative RC-Framed Skin for Seismic Retrofit Intervention on Existing Buildings
}

\author{
Diego Alejandro Talledo ${ }^{1}$, Irene Rocca ${ }^{1}$, , Luca Pozza ${ }^{2}$, Marco Savoia ${ }^{2}$ and Anna Saetta ${ }^{1, *}$ \\ 1 Department of Architecture and Arts (DCP), University IUAV of Venice, 30135 Venezia, Italy; \\ dtalledo@iuav.it (D.A.T.); irocca@iuav.it (I.R.) \\ 2 Department of Civil, Chemical, Environmental and Materials Engineering (DICAM), University of Bologna, \\ 40126 Bologna, Italy; luca.pozza2@unibo.it (L.P.); marco.savoia@unibo.it (M.S.) \\ * Correspondence: saetta@iuav.it
}

check for

updates

Citation: Talledo, D.A.; Rocca, I.;

Pozza, L.; Savoia, M.; Saetta, A.

Numerical Assessment of an

Innovative RC-Framed Skin for

Seismic Retrofit Intervention on

Existing Buildings. Appl. Sci. 2021, 11,

9835. https://doi.org/10.3390/

app11219835

Academic Editors: Pier Paolo Rossi and Melina Bosco

Received: 22 September 2021

Accepted: 18 October 2021

Published: 21 October 2021

Publisher's Note: MDPI stays neutral with regard to jurisdictional claims in published maps and institutional affiliations.

Copyright: (c) 2021 by the authors. Licensee MDPI, Basel, Switzerland. This article is an open access article distributed under the terms and conditions of the Creative Commons Attribution (CC BY) license (https:// creativecommons.org/licenses/by/ $4.0 /)$.

\begin{abstract}
The seismic safety of existing building stock has become a very critical issue in recent years, mainly in earthquake-prone South Europe where most of the buildings were designed before the enforcement of seismic standards. Therefore, the concept, development and testing of efficient and cost-effective seismic retrofitting technologies are nowadays strongly needed, both for the society and for the scientific community. This study deals with the seismic assessment of a new RC-framed skin for retrofit intervention of existing buildings, evaluated through nonlinear static (pushover) analyses. A preliminary description of the proposed technology is provided, then numerical modeling of a typical RC existing building before and after retrofitting intervention is performed within the OpenSees framework. The results revealed that the proposed retrofitting technology improves the seismic performance of the RC building, also modifying the failure mode from a brittle soft-story mechanism to a more ductile one. The presented study, dedicated to the structural aspects of the system, is part of the TIMESAFE research project, where the thermo-hygrometric and acoustic performances achievable by the proposed RC-framed skin are also investigated.
\end{abstract}

Keywords: RC-framed skin; seismic assessment; nonlinear static analysis; existing RC buildings; retrofitting intervention

\section{Introduction}

The seismic inadequacy of masonry and reinforced concrete (RC) existing building stock has been tragically highlighted by the strong earthquakes occurred in the last decade in South Europe. Actually, a number of these buildings, not designed according to seismic standards (they are commonly named gravity load designed, GLD, buildings), collapsed or were severely damaged causing the loss of human lives and significant economic losses. Moreover, most of these existing buildings have reached their nominal service life, exhibiting a significant decay of structural performance due to degradation phenomena, often not properly handled by an adequate maintenance program. Therefore, the need of efficient and cost-effective seismic retrofitting methods has become a priority for the society and for the scientific community in order to fulfill modern standards such as the Eurocodes (e.g., [1,2]).

In the last twenty years a number of systems have been proposed, developed, and experimentally tested for RC buildings retrofitting; see [3] for a thorough review carried out by subdividing the seismic upgrading techniques in two categories, i.e., local and global approaches depending on the level at which they operate: on single element or on the structure as a whole. Among others, in [4] externally anchored precast wall panels have been used for the seismic retrofitting of $\mathrm{RC}$ frame, with a significant reduction of the construction period and a limited invasiveness.

More recently, a number of technological systems developed for energy and seismic renovation intervention have been proposed, see [5] for a comprehensive state of the art of 
interventions techniques for RC-framed buildings. These integrated solutions are typically based on realization of an external seismic-resistant system. In this way, the interruption of the use of the building during the intervention is also avoided, which represents significant cost and social saving. Concerning intervention techniques for existing RC buildings, in [6] an innovative technique for the simultaneous seismic-energy retrofitting of old buildings has been proposed, by combining inorganic textile-based composites with thermal insulation. A technological double skin exoskeleton with dissipative elements has been proposed in [7], while a new RC infilled frames connected to the existing ones has been studied in [8]. An integrated solution based on an earthquake resistant exoskeleton constituted by steel braced frames has been proposed in [9]. Similarly, in [10] the idea of external steel exoskeletons has been investigated for multiple retrofitting alternatives. Finally, Cross Laminated Timber (CLT) panels have been also suggested for the external integrated energy-seismic retrofitting of existing RC buildings. As an example, in [11] the possibility of replacing existing masonry infill walls in RC frame buildings with CLT panels has been investigated. It is worth underling the high potential of such an intervention technique (e.g., low cost and invasiveness, low time of realization, and low carbon material use), even if the related theoretical study and experimental testing are still at a preliminary stage.

In this paper, the seismic performances of the new RC-framed skin for retrofit intervention on existing buildings developed within the TIMESAFE project [12] are analyzed by discussing the results of a number of nonlinear static (pushover) analyses carried out on both existing and retrofitted RC buildings.

The main features of the proposed RC-framed skin, briefly summarized in the next section, are thoroughly described in [13] where also its feasibility and sustainability are investigated by means of a holistic Life Cycle Assessment for environmental impact and Life Cycle Cost for an economic evaluation.

\section{RC-Framed Skin for Retrofit Intervention on Existing Buildings}

In this section, the main structural characteristics of the proposed RC-framed skin technology are briefly presented, together with a description of the in situ installation phases, which allow avoiding the interruption of use of the building and significantly reducing the invasiveness of the intervention.

Figure 1 shows the detail of the proposed retrofitting technology, which consists of a RC frame rigidly connected to the external façade of the existing building by means of anchor rods placed at every floor level. The anchor rods must be designed to guarantee the respect of the hierarchy of strength principle, i.e., the connections must be sized to withstand with adequate over-strength the shear actions, so behaving elastically for the target seismic action.

The RC-framed skin is casted on site by using prefabricated expanded polystyrene (EPS) modules as formwork, which ensures also the thermal enhancement of the building.

The proposed system is characterized by a modular geometry with variable dimensions for both beams and columns, variable RC reinforcement, and variable column interspace. All these parameters can be designed to achieve a specific target of seismic safety level. Actually, the geometric parameters of EPS modules, strictly related to both the cross sections and interspace of frame elements, can be optimized depending on the characteristics of the existing building and of the selected seismic action.

In detail, columns can be designed with a square cross-section in the range 150 to $300 \mathrm{~mm}$, while the transversal beams with a rectangular cross-section with base equal to the side of the column plus $50 \mathrm{~mm}$ and height variable in the range 300 to $500 \mathrm{~mm}$. Typical column interspace is $1200 \mathrm{~mm}$, but some adjustments are usually required to fit the façade opening geometry. The beams are placed in contact and connected with the existing structure in order to maximize the effectiveness of the connection system. 


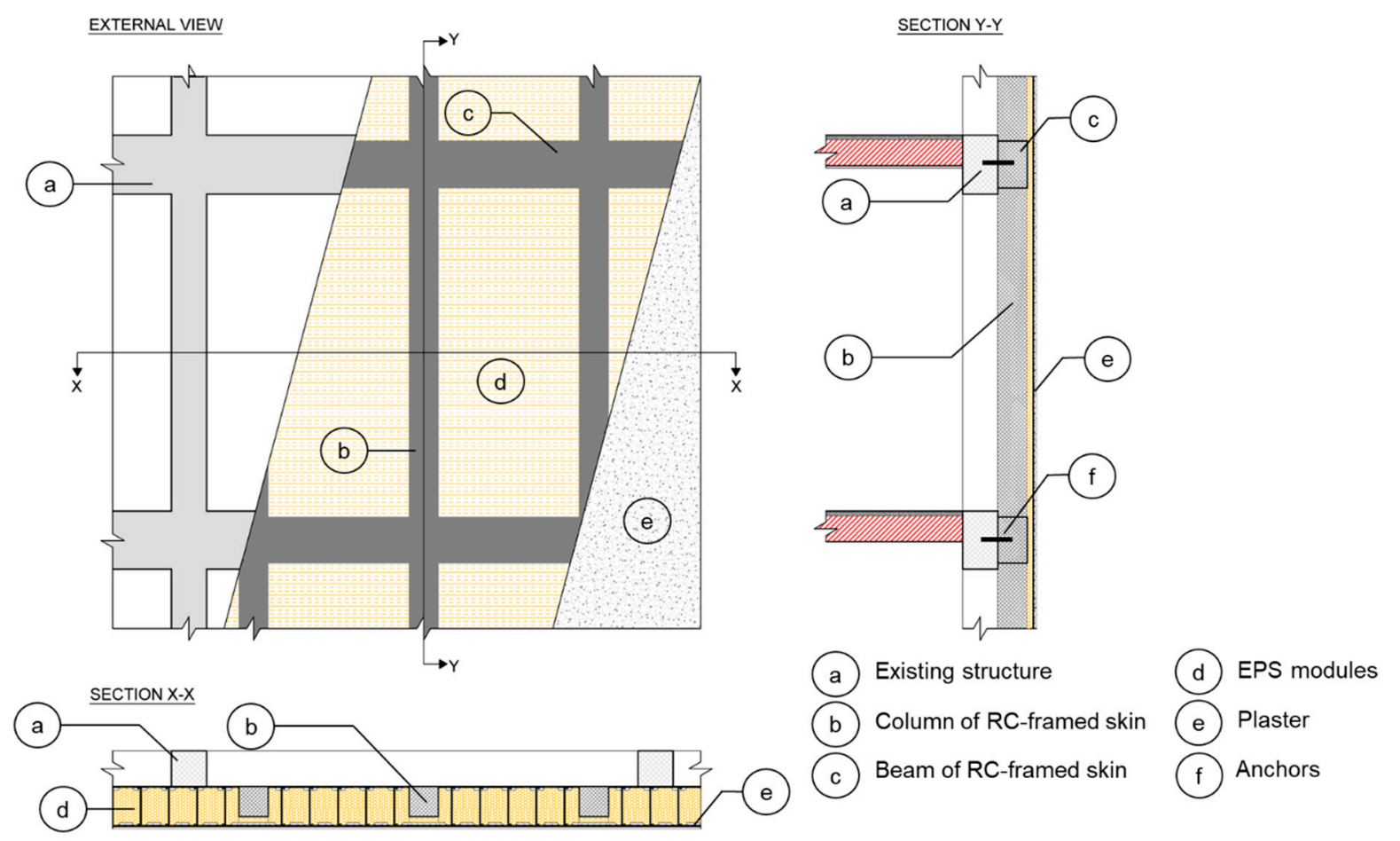

Figure 1. RC-framed skin.

Concerning the transversal reinforcement layout of the frame elements, continuous spirals are designed for the columns and rectangular stirrups for the beams. It is worth noting that, in order to ensure adequate confinement of the beam-column joint, the continuous spiral reinforcement of the column is provided across the joint itself.

The geometry of the system, and particularly of the EPS modules, is specifically shaped to realize an additional thick plaster on the external surface of the building. The external finishing plaster is reinforced with a steel mesh pre-assembled on the EPS modules and connected to the reinforcement of RC-framed skin by means of anchor rods.

The proposed retrofitting technology aims to limit invasiveness and interruption of use of the building; therefore, one of the main advantages of this technology is the possibility of working from the outside without internal intervention, by applying the RC-framed skin to the external façades.

The construction of the retrofitting system is of the platform type (i.e., floor by floor starting from the bottom) and consists of three main phases: (a) preparation of the façade and construction of the foundation beam; (b) installation of the prefabricated EPS modules and casting of the reinforcement frame; (c) realization of the external plaster and finishing of the façade, see [13] for the details.

It is worth noting that the existing foundation system may be inadequate for the new actions transmitted by the RC-framed skin, then, a simple connection to the existing foundation beams can be insufficient. In those cases, a retrofit of the foundation system may be needed. Nevertheless, the proposed technology provides for widespread interventions along the entire perimeter of the building, so generally leading to lower actions to the foundation if compared to the case of more localized retrofitted intervention, such as the addition of new shear walls.

\section{Numerical Strategies}

The structural behaviors of a typical GLD multi-story RC frame building constructed without any seismic detail, and of the same building retrofitted by using the proposed $\mathrm{RC}$-framed skin technology, are investigated by means of nonlinear static analysis. The 
Open System for Earthquake Engineering (OpenSees) framework [14] is adopted with the pre- and post-processor Scientific ToolKit for OpenSees (STKO) [15].

The modal analysis is performed to study the natural frequencies of both the existing and the retrofitted building, in order to compare the fundamental periods and evaluate the related displacement patterns, which are then assumed as the "modal" patterns within the nonlinear static analysis, according to Eurocode 8 [1].

\subsection{Nonlinear Static Analyses}

Concerning the nonlinear static analyses, after the application of the vertical loads, two vertical distributions of the lateral loads are applied, respectively: (i) a "uniform" pattern, based on lateral forces that are proportional to mass and (ii) a "modal" pattern, proportional to lateral forces consistent with first mode pattern obtained by the performed modal analysis. The structural performances of the existing and of the retrofitted building are discussed and compared in terms of capacity curves, i.e., the relations between base shear force and control node (top) displacement. In detail, peak shear force, ductility, and mode of failure are thoroughly evaluated and some considerations concerning the improvement obtained by retrofitting intervention are provided.

The numerical models are realized using a lumped plasticity approach with finite length of plastic hinges. Beams and columns are modelled as force-based nonlinear elements adopting the iterative flexibility formulation with the integration method proposed in [16], i.e., a modified two-point Gauss-Radau integration over each hinge region, so guaranteeing that localized deformations are integrated over the specified plastic hinge length. The length of the plastic hinge is evaluated according to the relation A.9 of EN1998-3 [2]:

$$
L_{p l}=\frac{L_{v}}{30}+0.2 h+0.11 \frac{d_{b L} f_{y}}{\sqrt{f_{c}}}
$$

where $L_{v}$ is the shear span assumed equal to half the length of the element, $h$ is the crosssection depth, $d_{b L}$ is the mean diameter of the tension reinforcement, and $f_{c}$ and $f_{y}$ are the concrete compressive strength $(\mathrm{MPa})$ and the steel yield strength $(\mathrm{MPa})$, respectively. The P-Delta effect is considered for the columns in all the performed nonlinear static analyses.

The constitutive model adopted for concrete is the one proposed by Mander et al. [17] (based on the equation proposed by Popovics [18]) for both existing RC building and RC-framed skin, while the model proposed by Menegotto-Pinto model, as modified by Filippou et al. [19], is adopted for steel. In the concrete model, a zero tensile strength is assumed and the compressive stress is set equal to zero when the crushing strain is achieved.

The concrete model adopted in the column cross section's core accounts for the effects of passive confinement. To this aim, the formulation proposed in Mander et al. [17] is considered in this work both for existing columns (with rectangular stirrups) and for the columns of the reinforcing RC-framed skin (with circular spirals).

Concerning the implementation phase, for the columns of the reinforcing RC-framed skin, an ad-hoc GUI (Graphical User Interface) for STKO [15] has been specifically developed providing a utility for users to input easily the geometric and material characteristics and computing automatically the effect of confinement on core material. In particular, the plugin recognizes the class of constitutive model adopted for cover concrete in OpenSees (e.g., Concrete01, Concrete02, Concrete04, etc.) and computes the effect of confinement according to several formulations, including the one developed by Mander et al. [17], adopted in this work as recommended in EN1998-3 [2] and Italian National Standard [20]. Finally, the plugin creates on the fly (when the model runs) a new material for core concrete (confined) of the same class of the unconfined concrete. Of course, the user always has the possibility to specify a customized confined material law when he does not want to use the plugin automatism. The window of the GUI for the reinforcing column of the RC-framed skin is shown in Figure 2, where both the constitutive laws adopted in this work for confined and unconfined concrete are depicted in terms of stress-strain curve. 


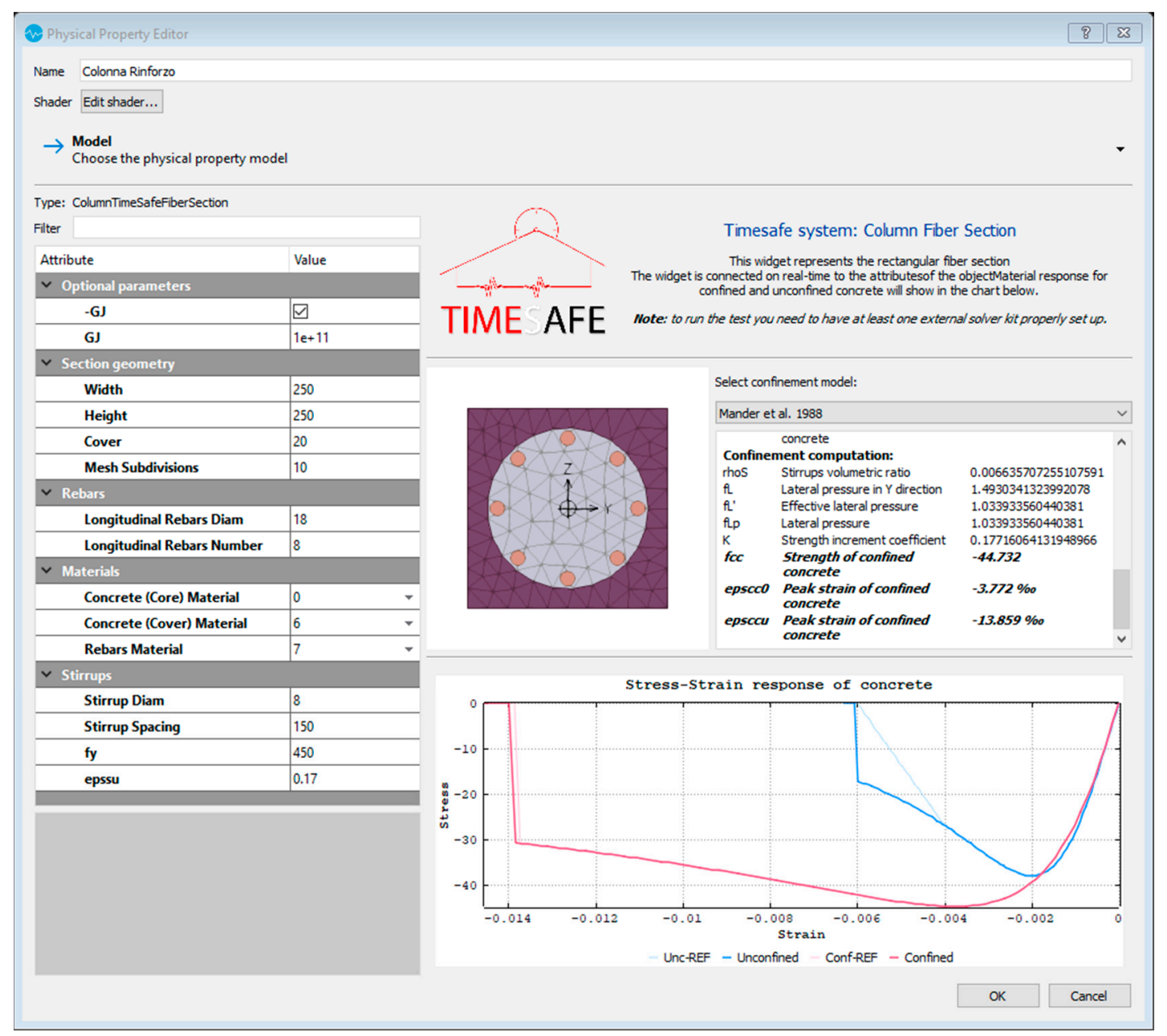

Figure 2. GUI developed for RC-framed skin column accounting automatically for effect of confinement.

\subsection{Structural Capacity Assessment}

After the nonlinear static analyses, both ductile and brittle mechanisms (i.e., shear) capacities are evaluated for all elements according to EN1998-3 [2].

In detail, for ductile mechanism, capacity checks are performed at the element level, evaluating the chord rotation demand and the corresponding capacity at the ends of each structural element (both beams and columns). The total chord rotation capacity at ultimate limit state (Near Collapse, NC) is evaluated according to the relation A.1 of EN1993-3 [2]:

$$
\vartheta_{u, m}=\frac{1}{\gamma_{e l}} 0.016 \cdot\left(0.3^{v}\right)\left[\frac{\max \left(0.01 ; \omega^{\prime}\right)}{\max (0.01 ; \omega)} f_{c}\right]^{0.225}\left(\min \left(9 ; \frac{L_{V}}{h}\right)\right)^{0.35} 25^{\left(\alpha \rho_{s x} \frac{f_{y w}}{f_{c}}\right)}\left(1.25^{100 \rho_{d}}\right)
$$

where $\gamma_{e l}$ is equal to 1.5 for primary seismic elements and to 1.0 for secondary seismic elements; $v$ is the axial load ratio; $\omega, \omega^{\prime}$ are the mechanical reinforcement ratios of the tension (including the web reinforcement) and compression longitudinal reinforcement; $\alpha$ is the confinement effectiveness factor; $\rho_{s x}, \rho_{d}$ are the ratios respectively of transverse steel parallel to the direction $x$ of loading, and of diagonal reinforcement (if any), in each diagonal direction; $f_{y w}$ is the stirrup yield strength (MPa). For RC existing frame designed without detailing for earthquake resistance, the value given by (1) must be divided by the factor 1.2.

Moreover, all the mean values of material strengths should be divided by the appropriate confidence factors based on the Knowledge Level, EN1998-3 [2]. The assessment with respect to Life Safety (LS) limit state refers to a chord rotation capacity equal to $3 v_{u, m} / 4$. 
For brittle mechanism, the shear demand is compared with the cyclic shear capacity for all elements evaluated according to the relation A.12 of EN1993-3 [2] (with units: MN and meters):

$$
\begin{aligned}
& V_{R}=\frac{1}{\gamma_{e l, s}}\left[\frac{h-x}{2 L_{v}} \min \left(N ; 0.55 A_{c} f_{c}\right)+\left(1-0.05 \min \left(5 ; \mu_{\Delta}^{p l}\right)\right)\right. \\
& \left.\cdot\left[0.16 \max \left(0.5 ; 100 \rho_{t o t}\right)\left(1-0.16 \min \left(5 ; \frac{L_{v}}{h}\right)\right) \sqrt{f_{c}} A_{c}+V_{w}\right]\right]
\end{aligned}
$$

where $\gamma_{e l, s}$ is equal to 1.15 for primary seismic elements and to 1.0 for secondary seismic elements; $x$ is the compression zone depth; $N$ is the compressive axial force (positive, taken as being zero for tension); $A_{c}=b_{w} \cdot d$ with $b_{w}$ the width and $d$ the effective depth of the cross-section; $\rho_{\text {tot }}$ is the total longitudinal reinforcement ratio; $V_{w}$ is the contribution of transverse reinforcement to shear resistance. According to the Biskinis model [21], adopted in EN1998-3 [2], the decrease of shear strength is assumed as a function of the plastic part of ductility demand $\mu_{\Delta}^{p l}=\mu_{\Delta}-1$ that can be calculated as the ratio between the plastic part of the chord rotation and the chord rotation at yielding. Note that shear resistance of primary seismic elements should be evaluated by adopting mean values of material strengths divided by the appropriate confidence factors based on the Knowledge Level and also by the partial factors for materials in accordance with EN1998-1 [22].

In the following analyses, a unitary confidence factor is assumed with the aim of evaluating the level of improvement attainable by adopting the proposed retrofitting technology in the limit case of maximum Knowledge Level for the existing building.

The attainment of ductile and brittle failures in the first elements, according to Equations (2) and (3), is marked in the capacity curves using for chord rotation capacity a yellow circle and for shear capacity a green triangle. Moreover, the type of elements where the limit is reached is highlighted by the letter $C$ for column and B for beam (see also [23]).

Actually, the capacity curves are not interrupted when the first limit condition is reached but they continue up to a loss of at least $15 \%$ of the peak base shear capacity (according to Italian National Standard [20]), since the attainment of failure (whether ductile or brittle) in the first element is not assumed corresponding to failure of the whole structure, due to the 'conventional' nature associated with the definition of ultimate limit conditions.

For both RC existing and retrofitted building, in correspondence of specific steps of the loading history, the frame elements' state is represented to highlight where the limit conditions are reached, and the inter-story drift distribution is provided in order to support the interpretation of failure mechanisms and the validation of retrofitting measures.

\section{Existing RC Frame}

In this section the geometry, the loading conditions, and the material characteristics of a typical GLD multi-story RC frame representative of the Italian residential building stock of the 1970-1980s are described. Then, the main issues related to the numerical modeling approach adopted to assess the seismic performance of the selected building are illustrated and the results of static nonlinear analyses are presented.

\subsection{Geometry and Loading Conditions}

The selected building presents a rectangular plan with $14.30 \mathrm{~m} \times 18.30 \mathrm{~m}$ dimensions and 3.30 to $3.50 \mathrm{~m}$ inter-story height, Figure 3. The geometrical characteristics of frame elements, as well as their reinforcement ratios, have been derived from a simulated design performed only for gravity load, according to the technical standards and design rules in force in the 1980s. 


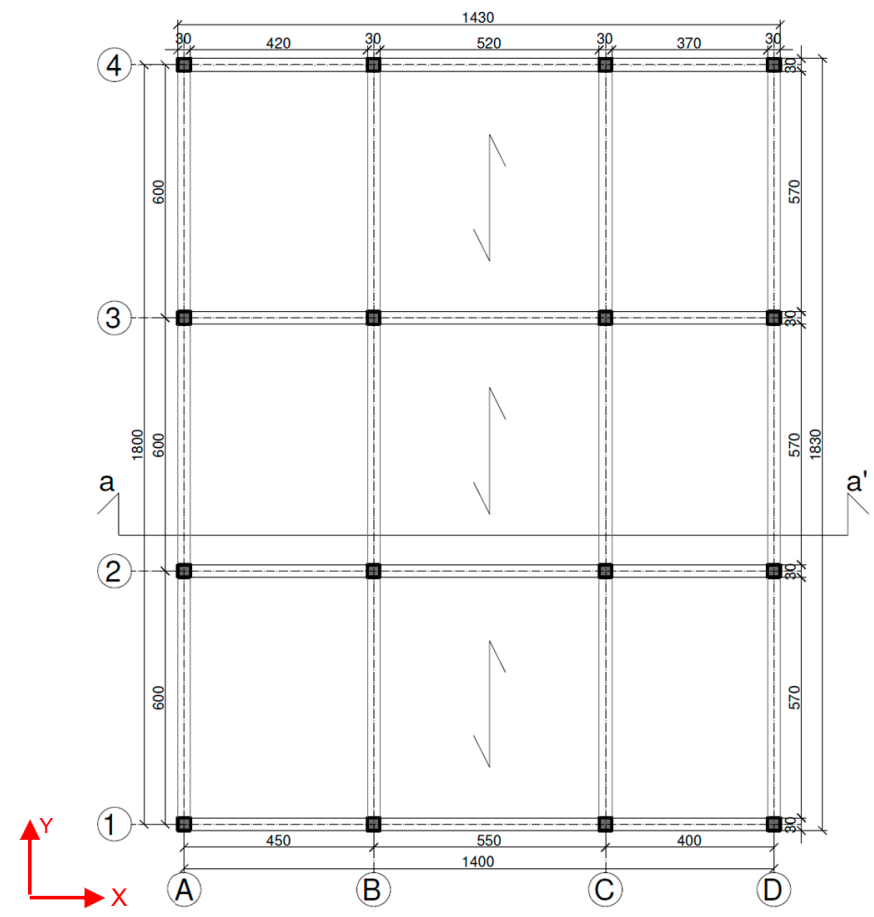

(a)

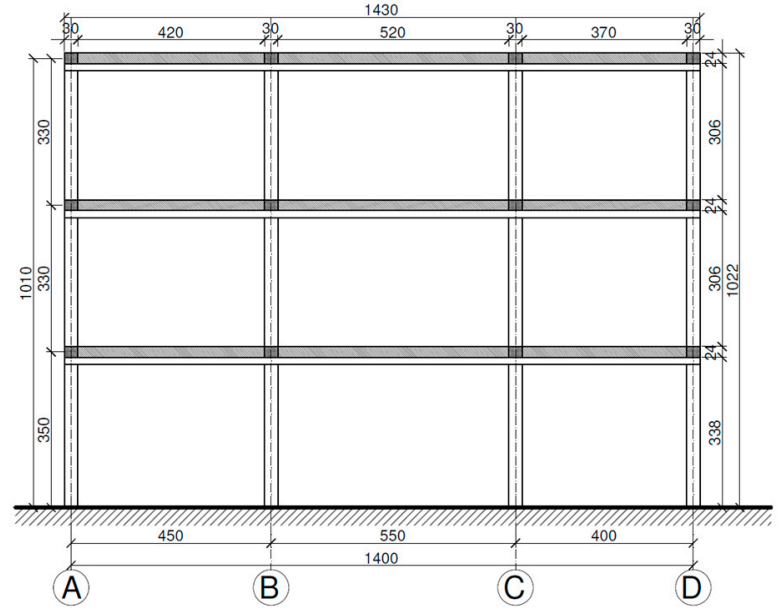

(b)

Figure 3. Three-story RC building: (a) Plan; (b) transversal view (units in $\mathrm{cm}$ ).

The building has four lateral-load resisting frames along the transversal X direction, with constant beam cross-section $300 \mathrm{~mm} \times 400 \mathrm{~mm}$. Along the longitudinal Y direction, there are only two external frames where the columns are connected through a flat beam with cross section $300 \mathrm{~mm} \times 240 \mathrm{~mm}$. All the columns have the same cross-section, $300 \mathrm{~mm} \times 300 \mathrm{~mm}$. The reinforcement layouts of the typical cross-sections of the frame elements are shown in Figures 4 and 5. It is worth remarking that all RC elements are designed without any seismic detail.

Gravity loads are represented by a dead load of $5.00 \mathrm{kN} / \mathrm{m}^{2}$ on the top floor and $6.0 \mathrm{kN} / \mathrm{m}^{2}$ on the other floors. The live load is assumed $1.2 \mathrm{kN} / \mathrm{m}^{2}$ on the top floor and $2.0 \mathrm{kN} / \mathrm{m}^{2}$ on all the other floors corresponding to residential category (i.e., imposed load on floors, category A according to EN 1991-1-1 [24]). An average weight of $6.25 \mathrm{kN} / \mathrm{m}$ per unit length has been considered for external masonry infills.

\subsection{Numerical Modeling}

In this section, some issues related to the numerical modeling of the existing building are provided and the main results of pushover analyses are presented. All the displacements and rotations of the existing RC frame base nodes are fully restrained.
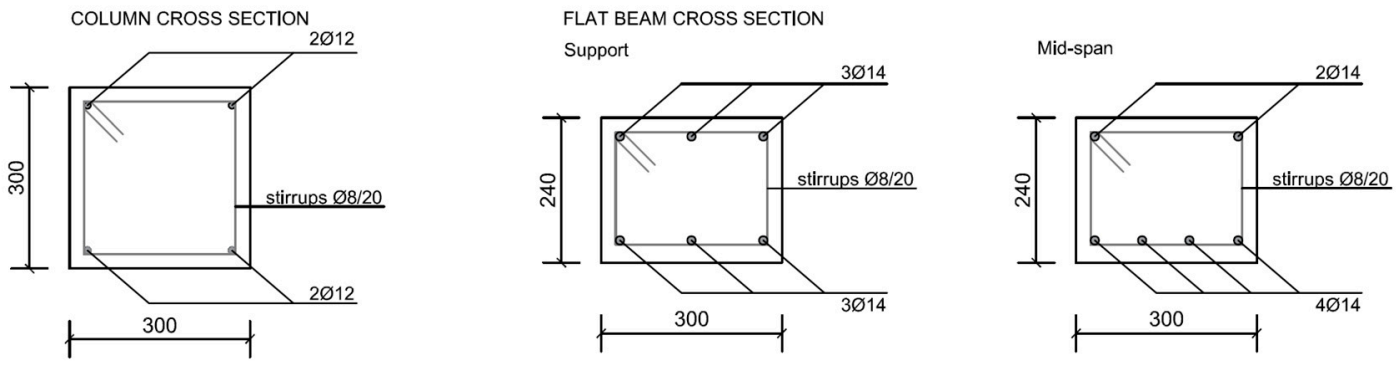

Figure 4. Three-story RC building. Reinforcement layout of RC element cross-sections: column and external flat beams in the weak $Y$ direction (units in $\mathrm{mm}$ ). 

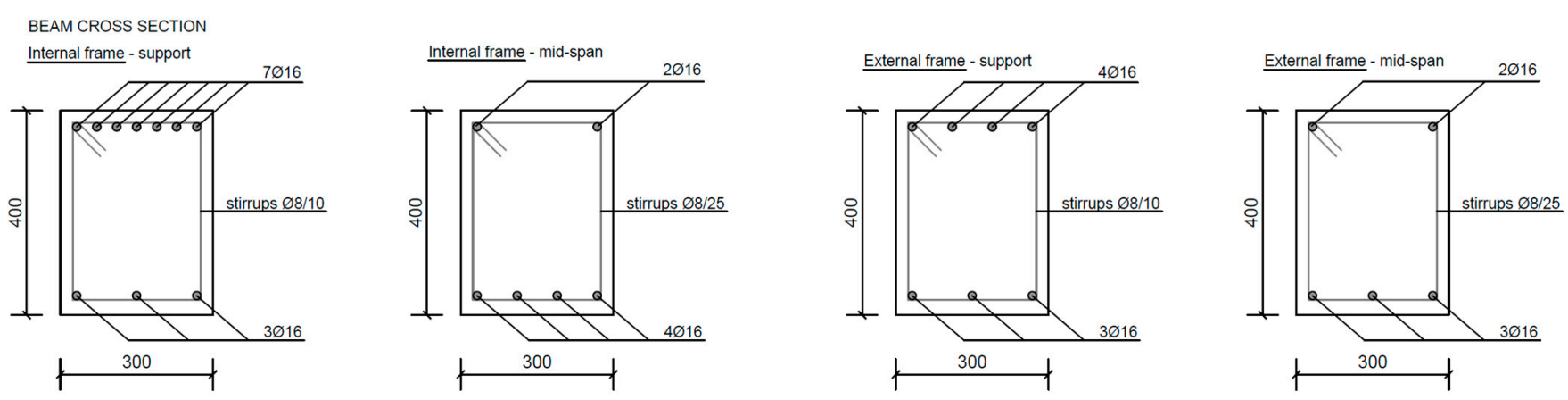

Figure 5. Three-story RC building. Reinforcement layout of RC element cross-sections: beams in the strong X directions (units in $\mathrm{mm}$ ).

\subsubsection{Material Properties}

The material properties of both concrete and steel reinforcement of the existing building are summarized in Table 1. The concrete is assumed as a C25 grade according to Model Code 2010 [25], and the corresponding mean compressive value is evaluated as $f_{c m}=f_{c k}+\Delta f$ with $\Delta f=8 \mathrm{MPa}$ [25]. The mean yield strength, the hardening ratio, and the ultimate strain of steel reinforcement are evaluated by means of STIL software developed by Verderame et al. [26], based on an extensive database of experimental tests on reinforcing bars collected from samples of the second half of the last century. In particular, almost 2500 samples of steel were selected within the period 1970 and 1990, computing the mean and standard deviation of yield strength, hardening ratio, and ultimate strain.

Table 1. Material properties for existing RC frame.

\begin{tabular}{ccc}
\hline Material & Property & Value \\
\hline & Mean compressive strength & $33 \mathrm{MPa}$ \\
Concrete: C25 & Strain at peak stress & 0.002 \\
& Ultimate strain & 0.006 \\
\hline \multirow{2}{*}{ Steel: FeB44k } & Mean yield strength & $510 \mathrm{MPa}$ \\
& Hardening ratio & 1.52 \\
& Ultimate strain & $21.7 \%$ \\
\hline
\end{tabular}

${ }^{1}$ The hardening ratio is defined as ultimate strength over yield strength $f_{u} / f_{y}$.

\subsubsection{Nonlinear Static Analysis}

In this section, the main results in terms of capacity curves and distribution of plastic hinges at different time steps of the analysis are presented for both the strong and the weak directions, e.g., the $X$ and $Y$ direction, respectively.

As for the plastic hinge lengths, according to relation (1), for the existing frame they are in the range $300-330 \mathrm{~mm}$ for the deep beams, depending on their length, $290 \mathrm{~mm}$ for the flat beam, and $235 \mathrm{~mm}$ for the columns.

The results in terms of base shear vs. top displacement curves are reported for $X$ (strong) direction in Figure 6a and for $\mathrm{Y}$ (weak) direction in Figure 6b. In both cases, the two distributions of the lateral loads are applied, according to the first mode and to a uniform pattern proportional to mass. The capacity in terms of base shear is, in the weak $Y$ direction, about half with respect to $X$ direction. The attainment of the LS chord rotation capacity in the first column of the existing frame occurs after about $30 \mathrm{~mm}$ from the peak in both pushover analyses (uniform and modal) in the $X$ direction, while for the analyses in the $Y$ direction the rotation capacity of the first column at the ground floor is achieved just after the beginning of the softening branch. Moreover, in $Y$ direction the flat beams achieve their shear capacity close to the peak of the curve. 


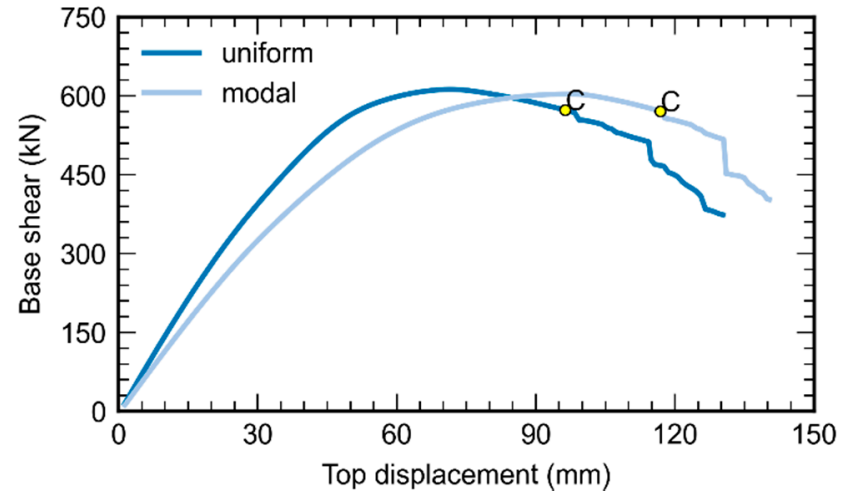

(a)

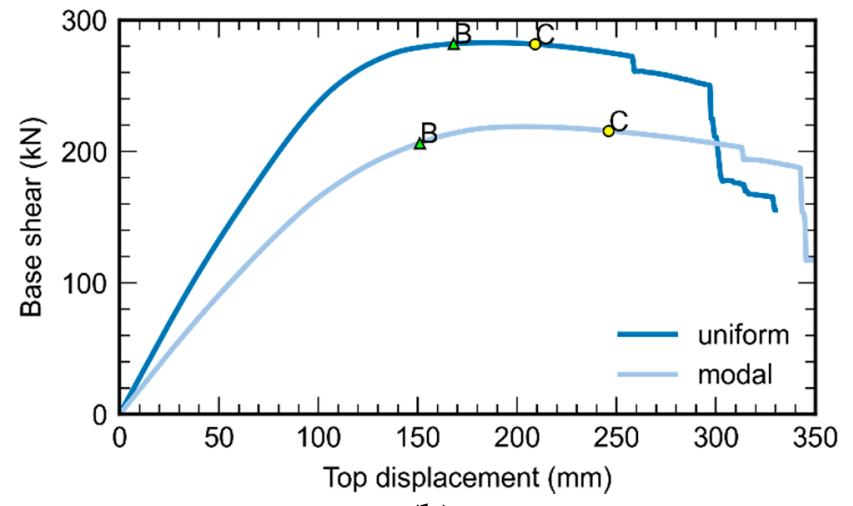

(b)

Figure 6. Capacity curves for RC existing building: (a) X direction; (b) Y direction. A yellow circle indicates the attainment of the LS chord rotation capacity and a green triangle the attainment of the shear capacity. The type of elements where the limit is reached is marked by the letter $\mathrm{C}$ for column and $\mathrm{B}$ for beam.

The failure mechanisms can be inferred by observing the evolution of the curvatures of the sections at the column and beam extremities during the analyses, reported in Figures 7 and 8 for loading in $X$ and $Y$ direction, respectively. Actually, in the $X$ (strong) direction the first hinges occur at the base of the columns, with some hinges also at the top sections of the columns in the first and second floor, as shown in Figure 7a. Then, a soft-story mechanisms is clearly evidenced with plastic hinges in all of the columns of the ground floor at both base and top sections when the ultimate chord rotation capacity is attained, as depicted in Figure $7 \mathrm{~b}$.

As expected, the behavior in the $\mathrm{Y}$ (weak) direction is significantly different, with a much evident deformability (top displacement at maximum base shear almost three times greater than in the strong direction) and the formation of plastic hinges on the flat beams since the first steps of analysis and then a progressive formation of plastic hinges at the base of columns up to the structural failure (Figure 8).

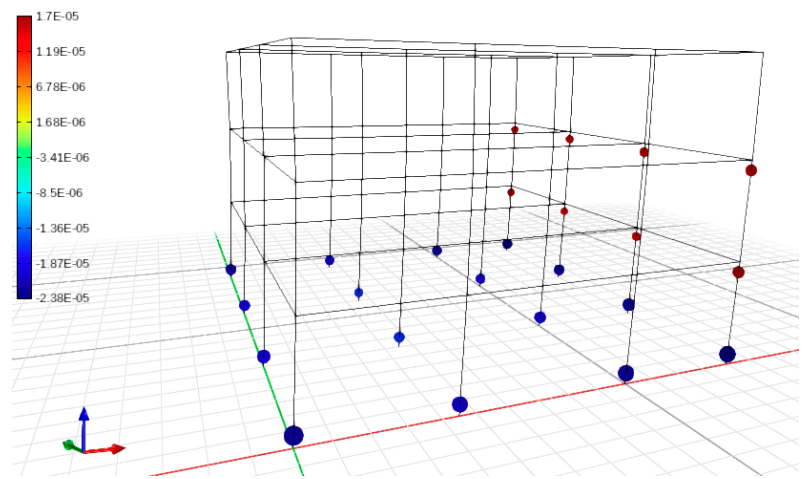

(a)

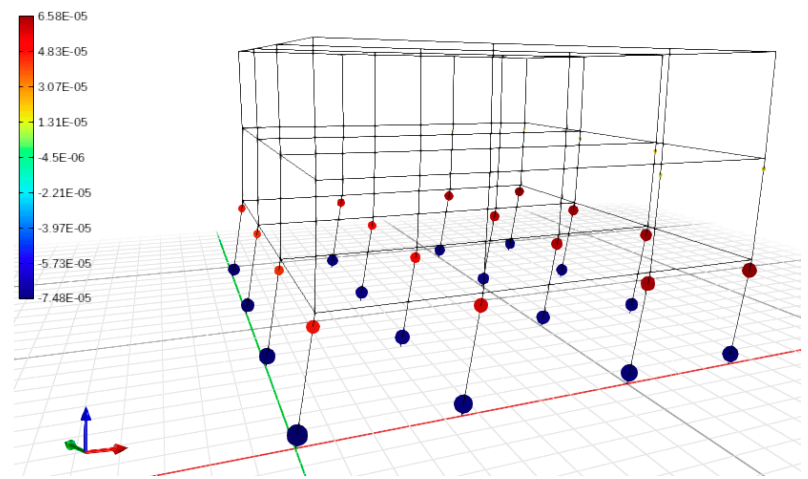

(b)

Figure 7. RC existing building, uniform pushover. Curvature distribution corresponding to a top displacement in $X$ direction of: (a) $50 \mathrm{~mm}$; (b) $95 \mathrm{~mm}$ (attainment of the LS chord rotation capacity). Red line X direction, green line $\mathrm{Y}$ direction. 


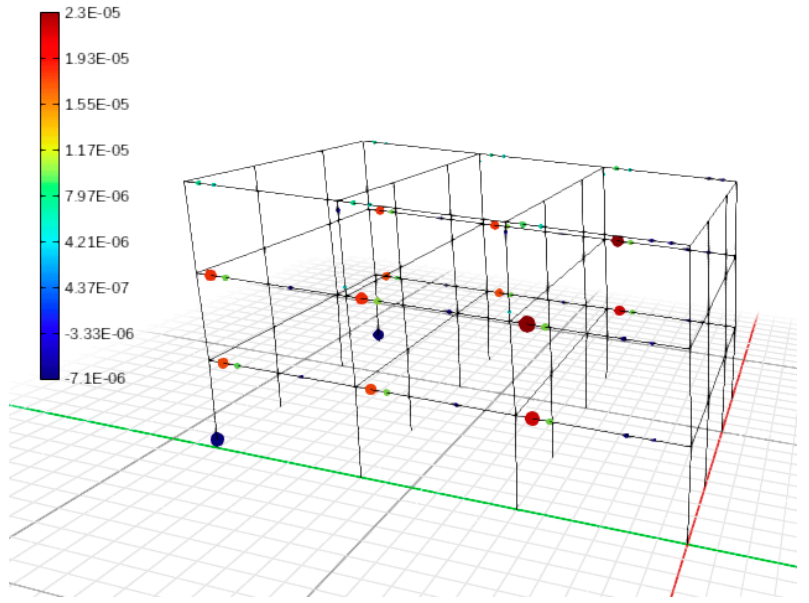

(a)

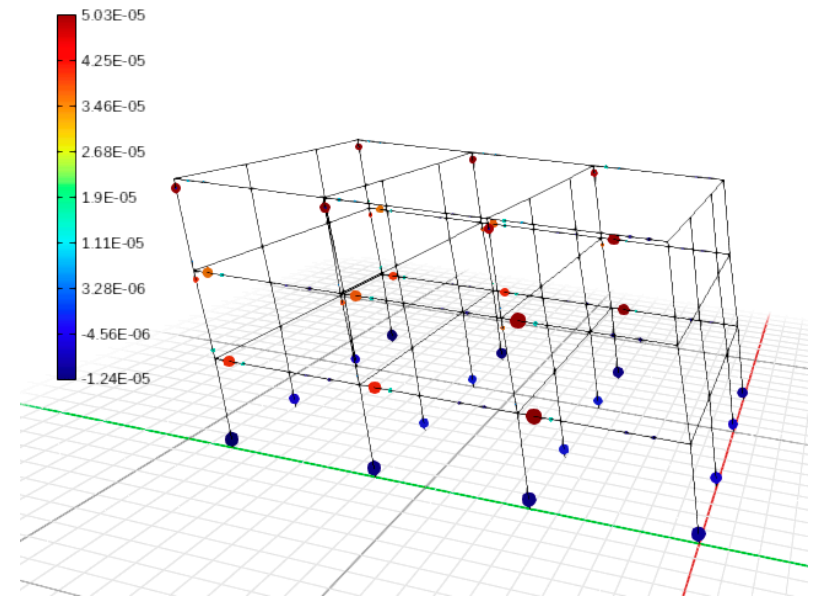

(b)

Figure 8. RC existing building, uniform pushover. Curvature distribution corresponding to a top displacement in $Y$ direction of: (a) $100 \mathrm{~mm}$; (b) $200 \mathrm{~mm}$ (attainment of the LS chord rotation capacity). Red line X direction, green line Y direction.

\section{Retrofitted Building}

In this section, the main characteristics of the existing building retrofitted by adopting the proposed new RC-framed skin are described, and the results of static nonlinear analyses are presented.

\subsection{Geometry and Reinforcement Details}

The proposed RC-framed skin is externally applied to the existing RC building described in the previous section and connected at each floor-level using anchor rods designed to guarantee a properly rigid connection as well as the respect of the hierarchy of strength principle. EPS modules $1200 \mathrm{~mm}$ wide and $325 \mathrm{~mm}$ thick are used to clad the structure. The adopted cross-sections for the RC-framed skin are $250 \mathrm{~mm} \times 250 \mathrm{~mm}$ for the columns and $250 \mathrm{~mm} \times 400 \mathrm{~mm}$ for the beams, respectively.

The geometry of the retrofitted building is depicted in Figure 9, where the spacing of the column is selected according to the opening layout of the existing building. Figure 10 shows the 3D view of retrofitted building, while Figure 11 shows the reinforcement layout of beam and column cross-sections of the RC-framed skin.

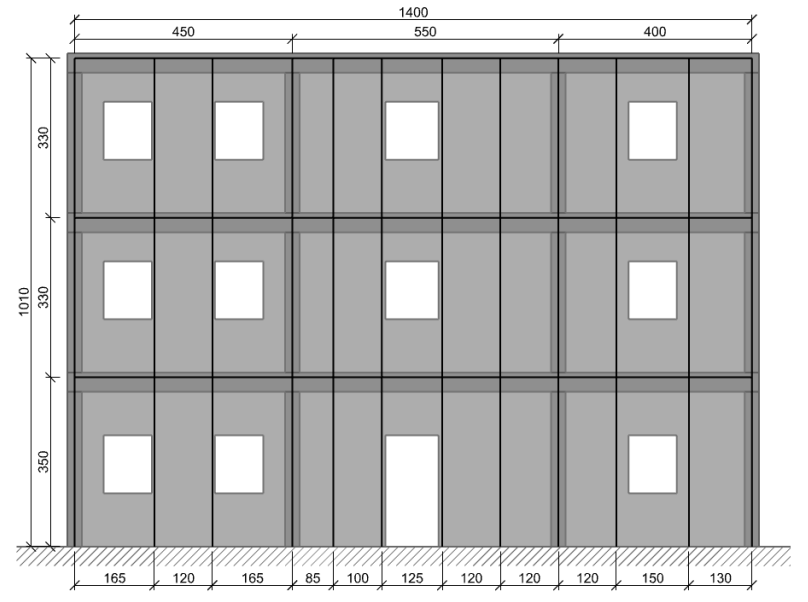

(a)

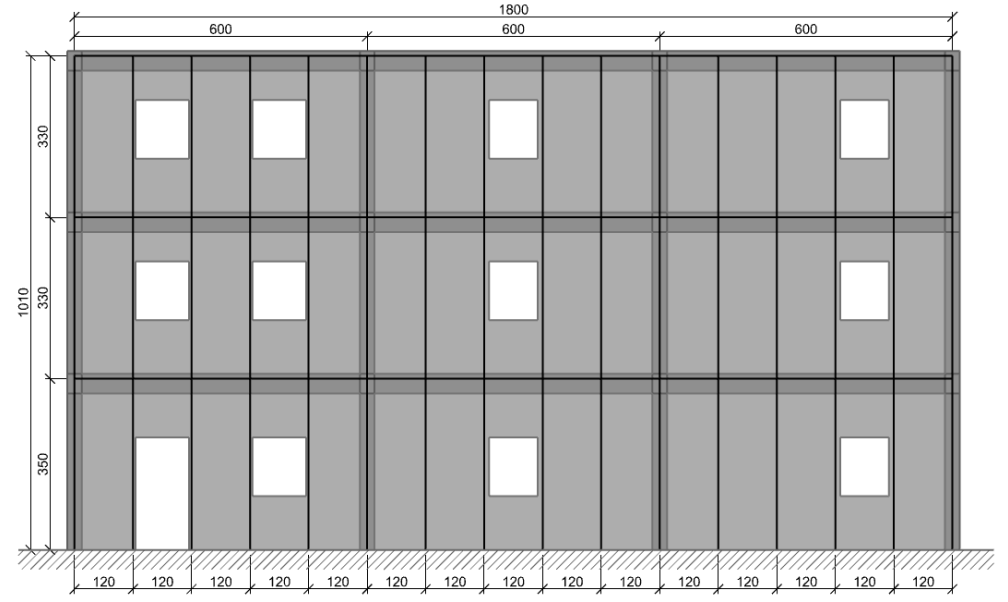

(b)

Figure 9. RC-framed skin applied to the existing RC building with evidenced the opening lay-out: (a) transversal view; (b) longitudinal view. 


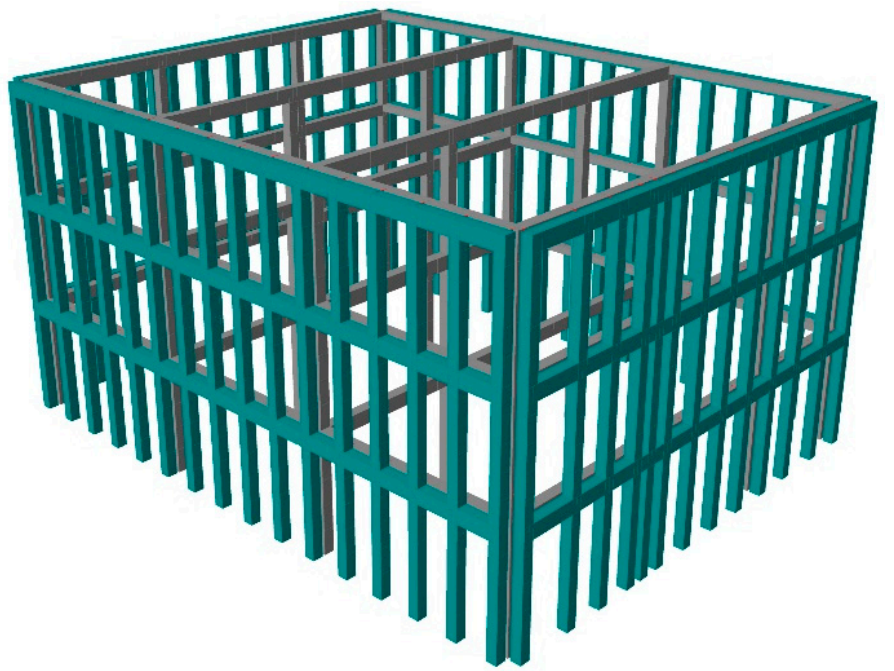

Figure 10. RC-framed skin as reinforcement for the existing RC building: 3D view.

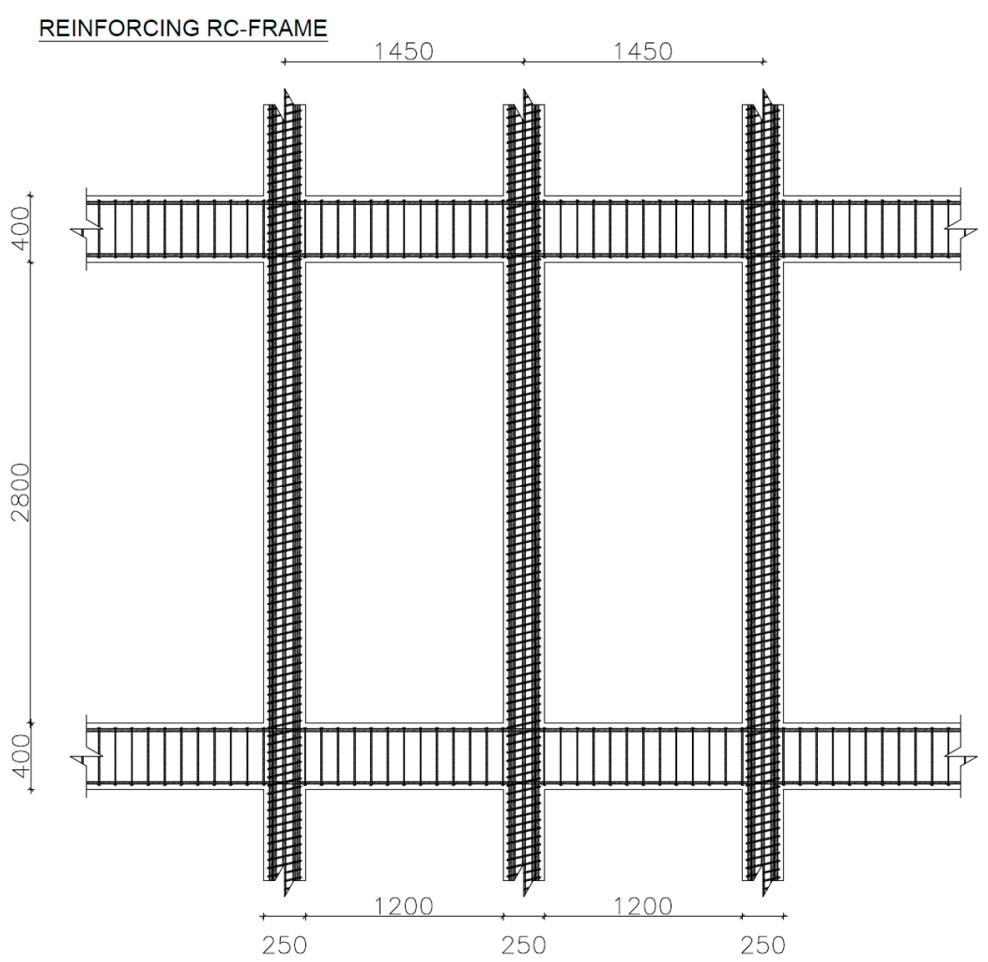

(a)

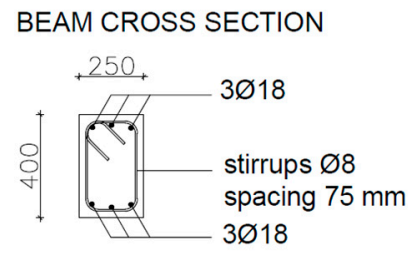

COLUMN CROSS SECTION

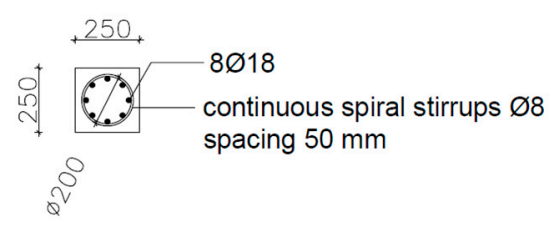

(b)

Figure 11. RC-framed skin: (a) reinforcement layout; (b) beam and column cross-sections.

\subsection{Numerical Modeling}

The RC-framed skin is modeled as connected to the existing structure by means of kinematic constraints imposing the equality of the horizontal and vertical displacement, while the base nodes are all fixed.

\subsubsection{Material Properties}

The material properties of both concrete and steel reinforcement of the RC-framed skin are summarized in Table 2. The concrete is assumed as a C30 grade according to Model Code 2010 [25], while the steel reinforcement is assumed equivalent to a B450C type. 
Mean yield strength, hardening ratio, and ultimate strain of steel are taken from available experimental results [23].

Table 2. Material properties for RC-framed skin.

\begin{tabular}{ccc}
\hline Material & Property & Value \\
\hline & Compressive strength & $38 \mathrm{MPa}$ \\
Concrete: C30 & Strain at peak stress & 0.002 \\
& Ultimate strain & 0.006 \\
\hline \multirow{2}{*}{ Steel: B450C } & Yield strength & $514 \mathrm{MPa}$ \\
& Hardening ratio & 1.19 \\
& Ultimate strain & $25.3 \%$ \\
\hline
\end{tabular}

${ }^{1}$ The hardening ratio is defined as ultimate strength over yield strength $f_{u} / f_{y}$.

\subsubsection{Nonlinear Static Analysis}

In this section, the main results in terms of capacity curves and distributions of plastic hinges at different time steps of the analysis are presented, for seismic action in $\mathrm{X}$ and $\mathrm{Y}$ directions.

The plastic hinge lengths, for the RC-framed skin elements according to relation (1), are about $280 \mathrm{~mm}$ for the beams and $285 \mathrm{~mm}$ for the columns.

The results in terms of base shear vs. top displacement curves are reported for $X$ (strong) direction in Figure 12a and for Y (weak) direction in Figure 12b, for both the lateral forces distribution, i.e., uniform and modal. Due to the effect of the reinforcing RC-skin frame, the capacity in terms of base shear is significantly higher than the capacity of the existing building and the values for actions in $\mathrm{X}$ and $\mathrm{Y}$ directions are now comparable, leading to a structure without a weak direction. Actually, the capacity is slightly higher in the $Y$ direction respect to that in the $X$ direction, since there are more reinforcing columns along the sides parallel to $\mathrm{Y}$ direction. Moreover, it is possible to observe that, in both directions and for both pushover analyses (uniform and modal force distributions), the LS chord rotation capacity of the first column of the existing building is achieved just after the beginning of the softening branch.

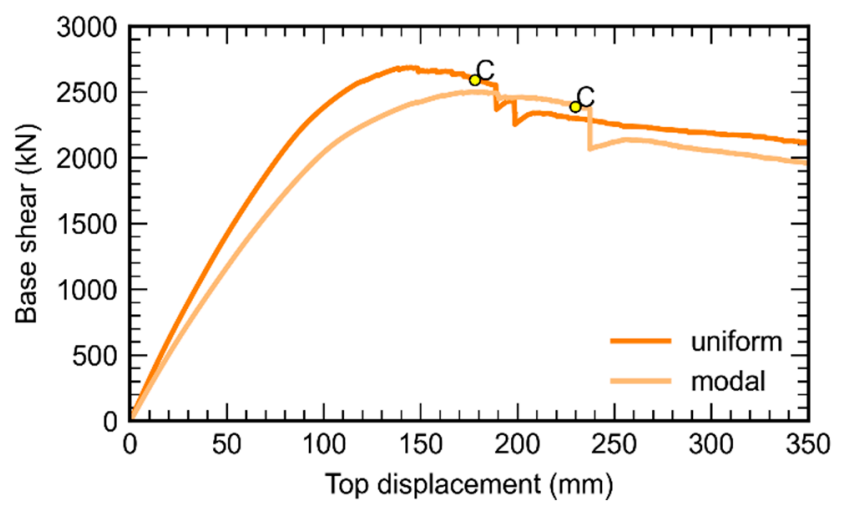

(a)

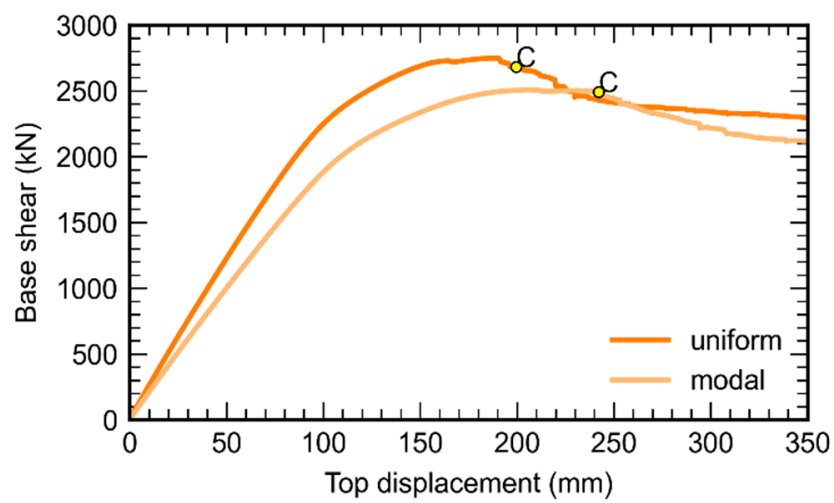

(b)

Figure 12. Capacity curves for the retrofitted building: (a) X direction; (b) Y direction. A yellow circle indicates the attainment of the LS chord rotation capacity and the type of elements where the limit is reached is marked by the letter C for column.

Figure 13 shows the curvature of the different sections at two steps of the pushover in $X$ direction with uniform distribution of forces: Figure 13a refers to yielding corresponding to a top displacement of about $100 \mathrm{~mm}$, while Figure $13 \mathrm{~b}$ refers to the attainment of ultimate chord rotation capacity in the columns of the existing building. It is possible to observe the mechanism with the formation of plastic hinges at the base and the top section of all the existing columns of the first floor and some of the existing columns of the second floor, 
together with the formation of plastic hinges in the columns of the reinforcement RC-skin frame in the first and second floor.

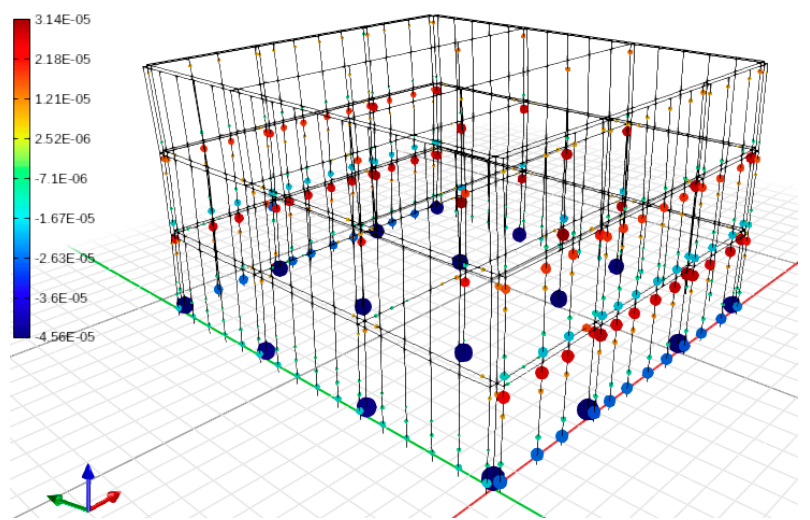

(a)

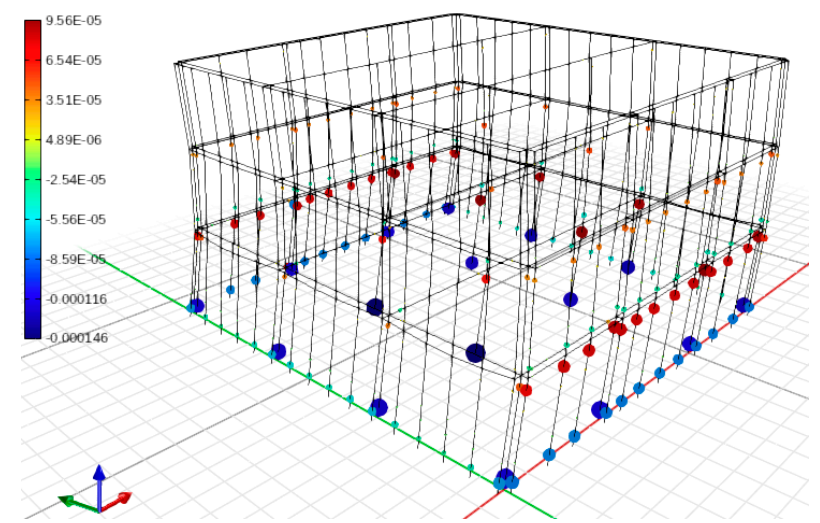

(b)

Figure 13. Retrofitted building, uniform pushover in $X$ direction. Curvature distribution corresponding to a top displacement of about: (a) $100 \mathrm{~mm}$; (b) $180 \mathrm{~mm}$ (attainment of the LS chord rotation capacity on a column of existing building).

Concerning the pushover in $\mathrm{Y}$ direction, Figure 14a depicts the curvature of the different sections for a top node displacement of about $100 \mathrm{~mm}$ : it is possible to observe that the plastic hinges occur at the bottom and top sections in the reinforcing columns at the first and second floor while, in the existing frame, the hinges are again at the base of the columns and on the flat beams. Figure $14 \mathrm{~b}$ shows the curvature corresponding to the attainment of LS chord rotation capacity of the columns of the existing building. It is interesting to note that no shear failure was detected on the existing flat beams, as opposed to the pushover in $Y$ direction of the existing building without reinforcement (see Section 4.2.2).

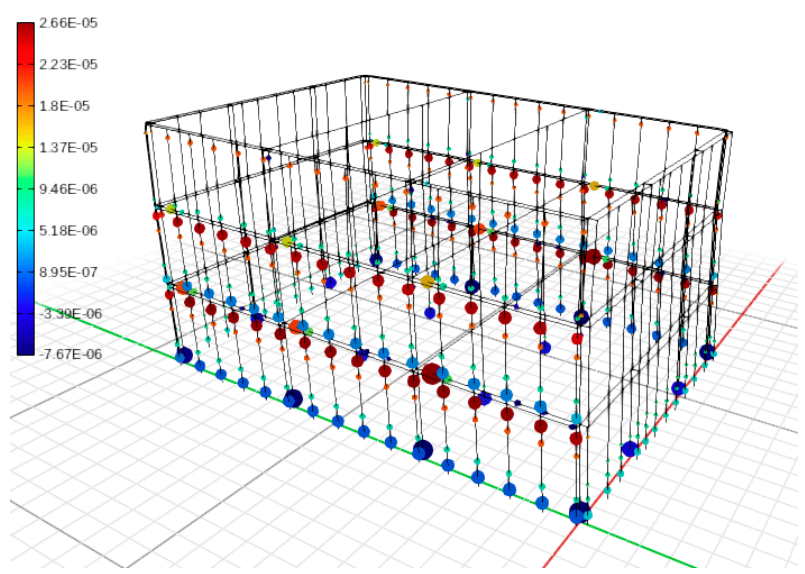

(a)

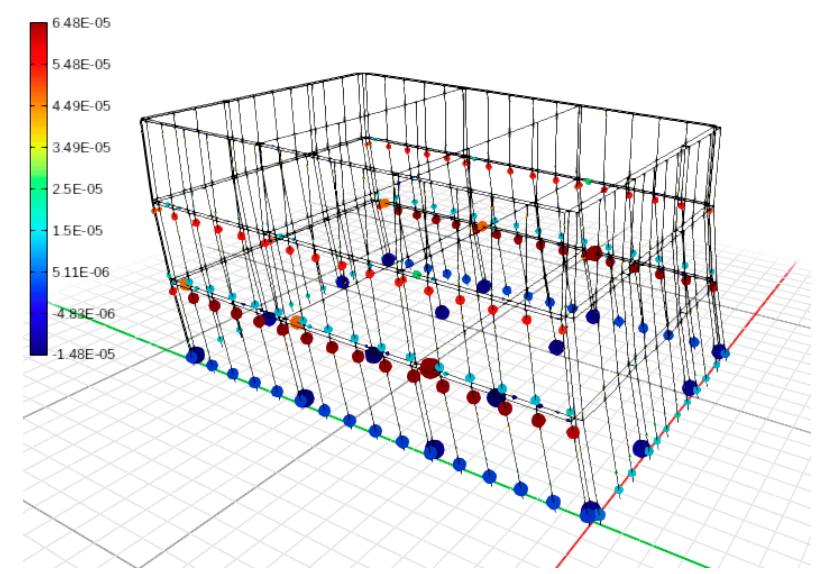

(b)

Figure 14. Retrofitted building, uniform pushover in $\mathrm{Y}$ direction. Curvature distribution corresponding to a top displacement of about: (a) $100 \mathrm{~mm}$; (b) $200 \mathrm{~mm}$ (attainment of the LS chord rotation capacity on a column of existing building).

\section{Discussion}

As presented in the previous sections, a set of pushover analyses are carried out on the existing RC building and on the retrofitted building. In this section, a critical discussion of the results obtained is provided, also comparing the capacity curves of the unreinforced and reinforced building with the performance of the RC-framed skin only.

As an example, Figure 15 shows the three curves (unreinforced building, reinforced building, RC-framed skin only) in the case of uniform pushover analysis, highlighting the effect of the proposed intervention in terms of maximum shear capacity that increases 
respectively of about 4.5 times in $X$ direction and more than 9 times in $Y$ direction, i.e., the weak direction of the existing building.

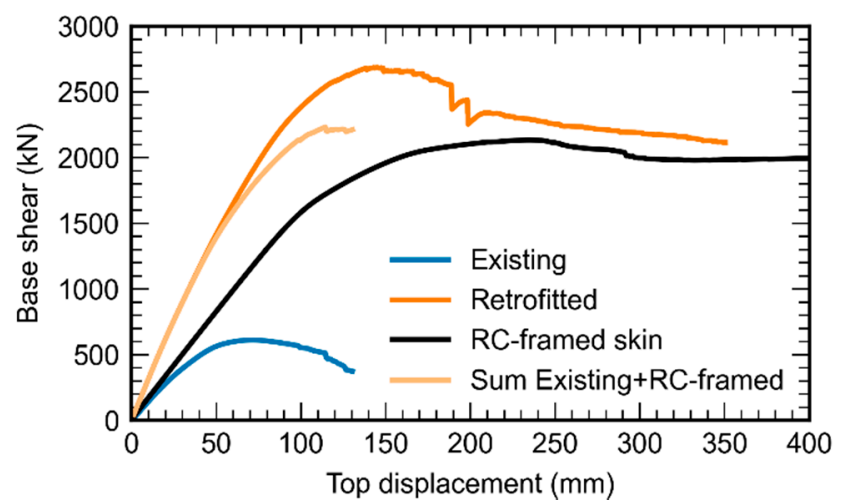

(a)

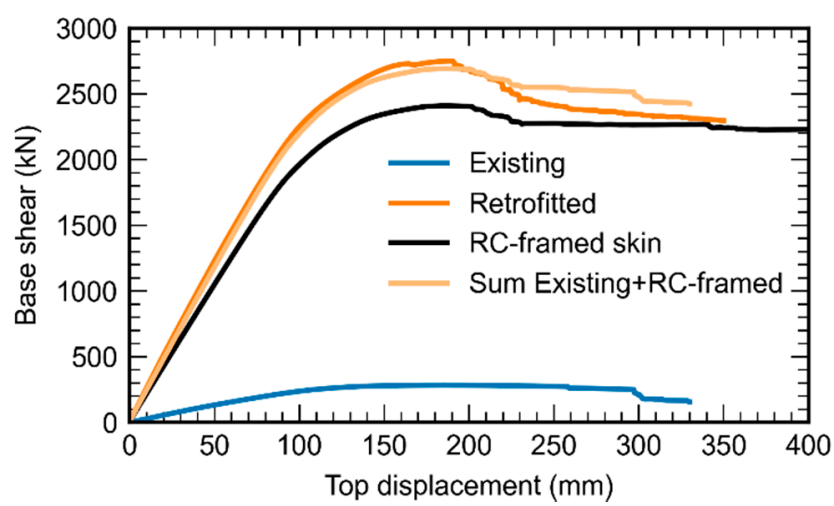

(b)

Figure 15. Uniform pushover analysis. Capacity curves of the existing RC building, the RC-framed skin, and the retrofitted building: (a) X direction; (b) Y direction.

It is possible also to see that the reinforcing frame increases significantly the stiffness of the building both in $X$ and $Y$ directions with an increase respectively of about 2 times and 10 times. The last very high value in the weak direction is due to the change of structural behavior from cantilever-like for the existing building to frame-like for the reinforced building. Of course, this aspect is important if the reinforcement is designed also to reduce the displacements and consequent damages to nonstructural components in the case of moderate earthquakes.

Concerning the displacement capacity, in X direction the displacement corresponding to the ultimate condition (attainment of ultimate chord rotation in columns) is increased of about $90 \%$.

Indeed, comparing Figure 13a with Figure $7 \mathrm{~b}$ it can be observed that, for a given value of top displacement, the reinforcement reduces the curvature at the bottom sections of the existing columns of almost $50 \%$, so avoiding the formation of the soft-story mechanism, because the deformations are better distributed along the height of the existing structure. On the other hand, in Y direction the ultimate displacement remains substantially the same if one considers the attainment of ultimate chord rotation, while it increases of about $20 \%$ if one considers the attainment of shear capacity in the flat beams of the existing building that is avoided in the retrofitted building.

Moreover, it is worth noting that the maximum shear capacity of the retrofitted building in the strong direction reaches a value higher than the simple superposition of the existing building and RC-framed skin results of about $20 \%$. This can be ascribed to the change in the mode of failure of the structure from a brittle soft-story collapse (for the existing building), to a more ductile one (for the retrofitted building), as described respectively in Section 4 (see also Figures 7 and 8) and in Section 5 (see also Figures 13 and 14). On the contrary, in the weak Y direction no difference between shear capacity of the retrofitted building and the simple sum of capacities of original structure and reinforcement is observed (Figure 15b).

The different failure-mode in the $\mathrm{X}$ direction for the retrofitted building with respect to the original building is also confirmed by the inter-story drift (ISD) distribution along the building height. Actually, Figures 16 and 17 show the evolution of the distributions of the ISD in the case of uniform pushover analysis for the existing RC building with and without retrofit measures. It is worth noting that the existing building exhibits a significant concentration of ISD in the ground floor story with seismic action in X direction, while the retrofitted building exhibits a more uniform distribution of drift, so demonstrating that a uniform distribution of both stiffness and strength is attained through the retrofit intervention. 

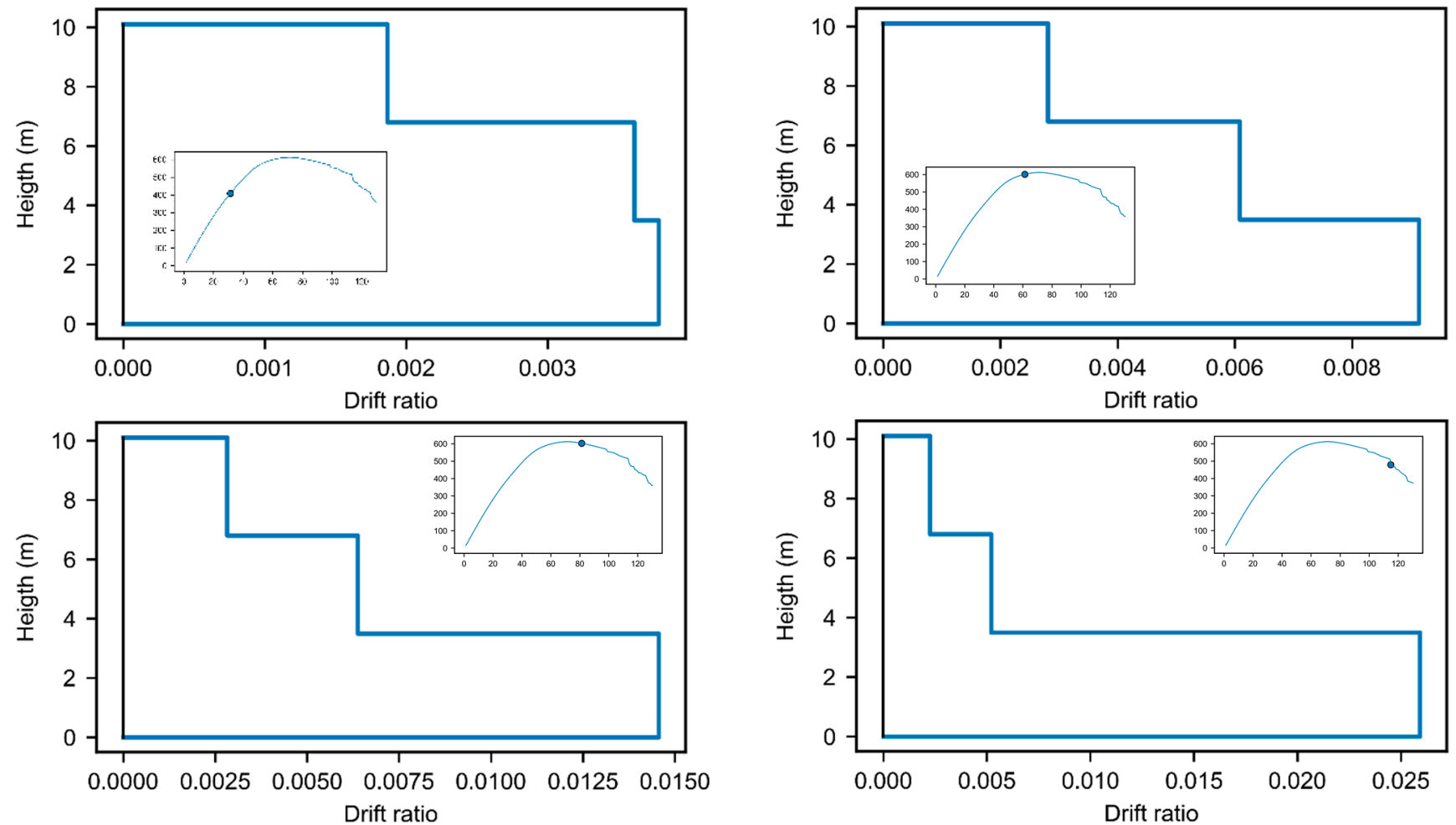

Figure 16. Existing building. Uniform pushover analysis in X direction: evolution of the inter-story drift distributions.
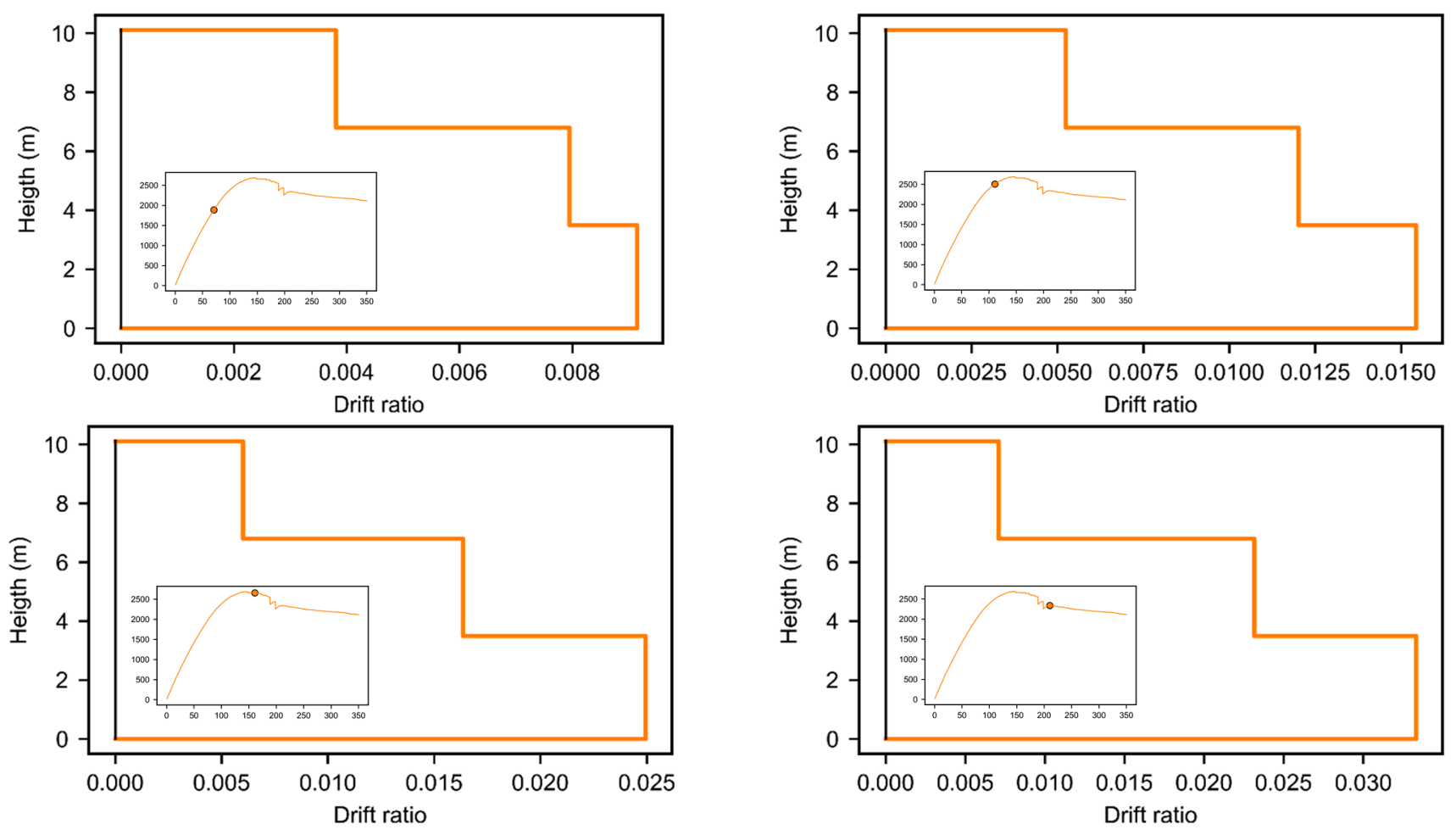

Figure 17. Retrofitted building. Uniform pushover analysis in $X$ direction: evolution of the inter-story drift distributions.

On the contrary, in the weak $\mathrm{Y}$ direction both the existing and retrofitted buildings (Figures 18 and 19) exhibit a more uniform distribution of drift. 

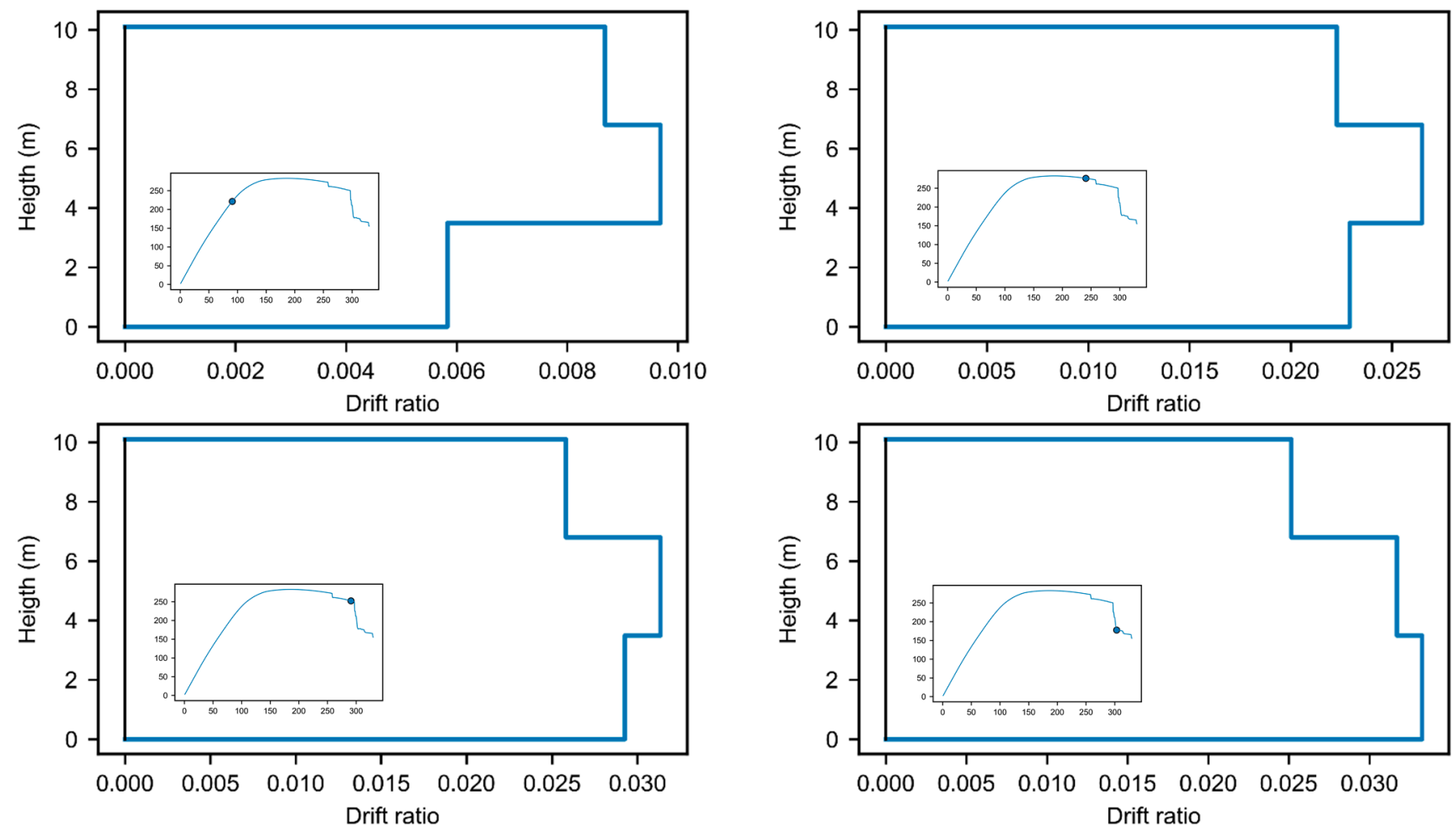

Figure 18. Existing building. Uniform pushover analysis in $Y$ direction: evolution of the inter-story drift distributions.
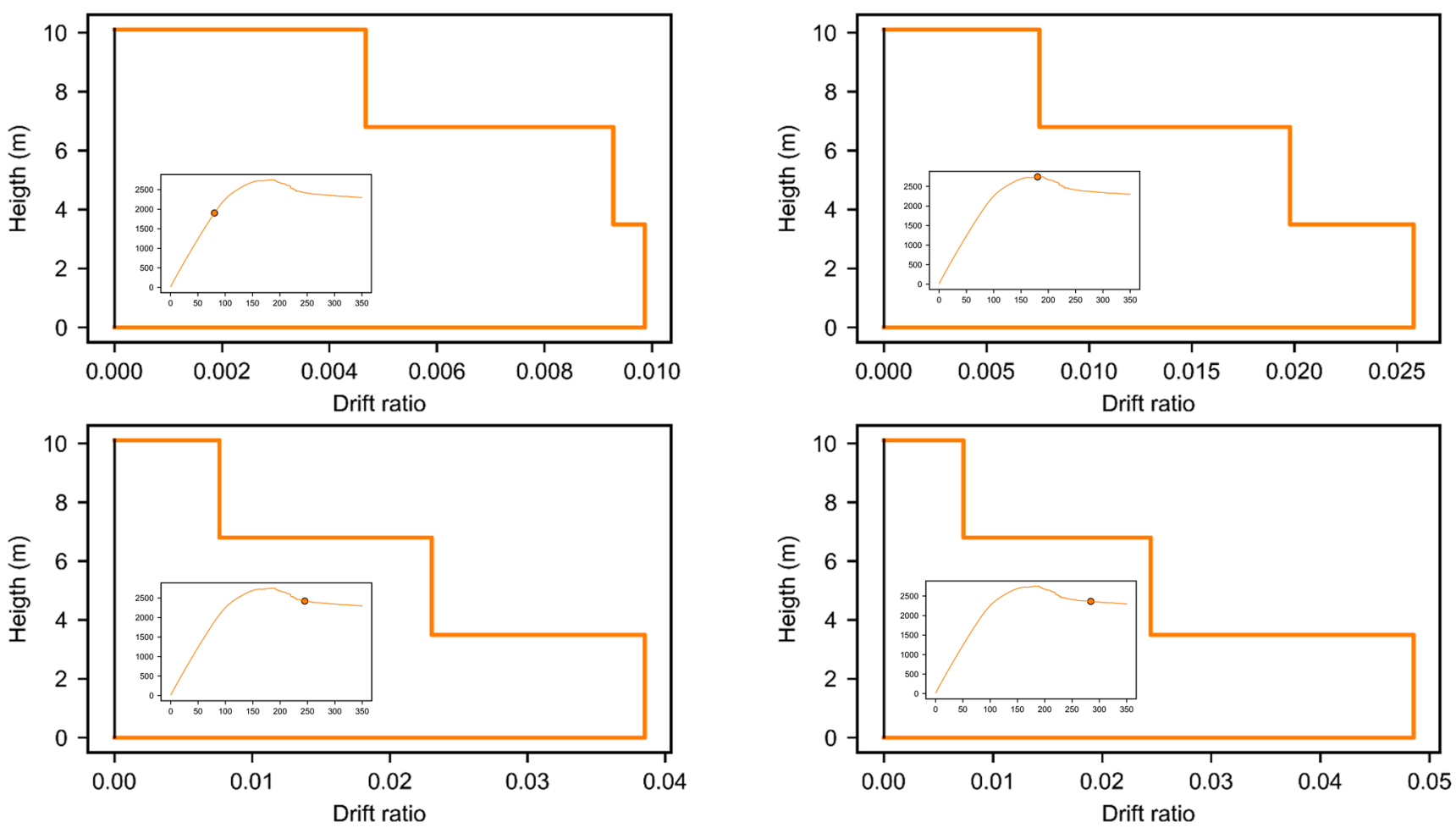

Figure 19. Retrofitted building. Uniform pushover analysis in $Y$ direction: evolution of the inter-story drift distributions.

\section{Conclusions}

The proposed RC-framed skin consists of cladding the existing building envelope with an innovative system, obtaining a retrofitted structure with a significant improvement of seismic performances, other than of energy efficiency, see also [13]. One of the main 
potentials of the proposed technology is the limit of invasiveness and the avoidance of the interruption of the building use during the intervention. This aspect, together with a holistic Life Cycle Assessment for environmental impact and a Life Cycle Cost for an economic evaluation are thoroughly discussed in [13].

Moreover, concerning the seismic behavior, the modularity of the proposed system allows for the design of the intervention perfectly suited to the specific RC existing building.

Actually, the proposed retrofitting technology overcomes the seismic deficiencies of most existing RC frame buildings located in earthquake-prone areas, providing the existing structure with significant increase of stiffness, strength, and often a more ductile failure model, as demonstrated by the pushover analyses carried out on a GLD existing RC building, on the RC-framed skin, and on the retrofitted building.

This research represents the preliminary stage of a more comprehensive project: experimental investigations are currently ongoing to better define the industrial production of the components, while numerical analyses will be carried out to evaluate the seismic behavior of different retrofitted buildings located in seismic-prone areas, by varying the geometry of the reinforcement (cross-section of columns and beams, spacing between columns) and the intensity of seismic action. Moreover, several configurations of existing buildings (with different shapes, like rectangular shapes with varying ratio between sides, or irregular shapes, like T, L, C, etc.) will be addressed in order to investigate the beneficial effect of the reinforcement RC-skin frame in regularizing the seismic behavior. These parametric analyses are the base for the definition of an optimization procedure to be adopted in the design phase of the retrofitting structure for instance in terms of geometric parameters of EPS modules and reinforcement of the RC-framed skin elements.

Finally, the use of proposed RC-framed skin technology for taller buildings will be tested. If the number of floors increases, the overall behavior of the reinforcement changes from a frame-like behavior experienced in the case study presented, to an overall flexural behavior similar to that typical of tube structures for tall buildings. In this case, also the stiffness of the transverse beams of the external reinforcement becomes relevant to limit the typical shear lag phenomenon which can reduce the efficiency of the system in real applications [27-29].

Author Contributions: Conceptualization, methodology, D.A.T. and L.P.; data curation, validation, visualization, D.A.T., I.R., A.S., and L.P.; software, D.A.T.; formal analysis, D.A.T. and I.R.; writingoriginal draft preparation, D.A.T., L.P., and A.S.; project administration, funding acquisition, M.S.; writing-review and editing, D.A.T., M.S., and A.S.; Supervision, M.S. and A.S. All authors have read and agreed to the published version of the manuscript.

Funding: This research was funded by Regione Emilia Romagna POR-FESR 2014/2020-Asse 1.2.2-project TIMESAFE-Tecnologie integrate ed innovative a limitato impatto ed invasività per il miglioramento sismico degli edifici senza interruzione d'uso"-CUP J44I18000070007-PG/2018/631222_16/10/2018.

Acknowledgments: The authors would like to thank Claudio Azzolini for the kind cooperation, Ing. Giacomo Mussoni for the collaboration during the development of his master's degree thesis, and Ing. Andrea Doria for his support.

Conflicts of Interest: The authors declare no conflict of interest.

\section{References}

1. EN 1998-1:2004. Eurocode 8: Design of Structures for Earthquake Resistance-Part 1-1: General Rules, Seismic Actions and General Requirements for Structures; European Committee for Standardization: Brussels, Belgium, 2004.

2. EN 1998-3:2005. Eurocode 8: Design of Structures for Earthquake Resistance_Part 3: Assessment and Retrofitting of buildings; European Committee for Standardization: Brussels, Belgium, 2005.

3. Gkournelos, P.D.; Triantafillou, T.C.; Bournas, D.A. Seismic upgrading of existing reinforced concrete buildings: A state-of-the-art review. Eng. Struct. 2021, 240, 112273. [CrossRef]

4. Choi, S.-H.; Hwang, J.-H.; Han, S.-J.; Joo, H.-E.; Yun, H.-D.; Kim, K.S. Seismic performance assessments of RC frame structures strengthened by external precast wall panel. Appl. Sci. 2020, 10, 1749. [CrossRef]

5. Margani, G.; Evola, G.; Tardo, C.; Marino, E.M. Energy, seismic, and architectural renovation of rc framed buildings with prefabricated timber panels. Sustainability 2020, 12, 4845. [CrossRef] 
6. Bournas, D.A. Concurrent seismic and energy retrofitting of RC and masonry building envelopes using inorganic textile-based composites combined with insulation materials: A new concept. Compos. Part B Eng. 2018, 148, 166-179. [CrossRef]

7. Marini, A.; Passoni, C.; Belleri, A.; Feroldi, F.; Preti, M.; Metelli, G.; Riva, P.; Giuriani, E.; Plizzari, G. Combining seismic retrofit with energy refurbishment for the sustainable renovation of RC buildings: A proof of concept. Eur. J. Environ. Civ. Eng. 2017, 1-21. [CrossRef]

8. Manfredi, V.; Masi, A. Seismic strengthening and energy efficiency: Towards an integrated approach for the rehabilitation of existing RC buildings. Buildings 2018, 8, 36. [CrossRef]

9. Ferrante, A.; Mochi, G.; Predari, G.; Badini, L.; Fotopoulou, A.; Gulli, R.; Semprini, G. A European project for safer and energy efficient buildings: Pro-GET-onE (proactive synergy of integrated efficient technologies on buildings' envelopes). Sustainability 2018, 10, 812. [CrossRef]

10. D'Urso, S.; Cicero, B. From the efficiency of nature to parametric design. A holistic approach for sustainable building renovation in seismic regions. Sustainability 2019, 11, 1227. [CrossRef]

11. Stazi, F.; Serpilli, M.; Maracchini, G.; Pavone, A. An experimental and numerical study on CLT panels used as infill shear walls for RC buildings retrofit. Constr. Build. Mater. 2019, 211, 605-616. [CrossRef]

12. TIMESAFE. Available online: http:/ / timesafe.it/ (accessed on 16 August 2021).

13. Pozza, L.; Esposti, A.D.; Bonoli, A.; Talledo, D.; Barbaresi, L.; Semprini, G.; Savoia, M. Multidisciplinary Performance Assessment of an Eco-Sustainable RC-framed skin for the integrated upgrading of existing buildings. Sustainability 2021, 13, 9225. [CrossRef]

14. McKenna, F.; Scott, M.H.; Fenves, G.L. Nonlinear finite-element analysis software architecture using object composition. J. Comput. Civ. Eng. 2010, 24, 95-107. [CrossRef]

15. Petracca, M.; Candeloro, F.; Camata, G. STKO User Manual; ASDEA Software Technology: Pescara, Italy, 2017.

16. Scott, M.H.; Fenves, G.L. Plastic hinge integration methods for force-based beam-Column elements. J. Struct. Eng. 2006, 132, 244-252. [CrossRef]

17. Mander, J.B.; Priestley, M.J.N.; Park, R. Theoretical stress strain model for confined concrete. J. Struct. Eng. 1988, 114, 1804-1826. [CrossRef]

18. Popovics, S. A numerical approach to the complete stress-strain curve of concrete. Cem. Concr. Res. 1973, 3, 583-599. [CrossRef]

19. Filippou, F.C.; Popov, E.P.; Bertero, V.V. Effects of bond deterioration on hysteretic behavior of reinforced concrete joints. In Report n. UCB/EERC 83-19; Earthquake Engineering Research Center, University of California: Springfield, MA, USA; Berkeley, CA, USA, 1983.

20. NTC 2018. Aggiornamento delle «Norme Tecniche per le Costruzioni»; MIT: Rome, Italy, 2018. (In Italian)

21. Biskinis, D.E.; Roupakias, G.K.; Fardis, M.N. Degradation of shear strength of reinforced concrete members with inelastic cyclic displacements. Struct. J. 2004, 101, 773-783. [CrossRef]

22. EN 1992-1-1:2004. Eurocode 2: Design of Concrete Structures-Part 1-1: General Rules and Rules for Buildings; CEN: Brussels, Belgium, 2004.

23. Berto, L.; Caprili, S.; Saetta, A.; Salvatore, W.; Talledo, D. Corrosion effects on the seismic response of existing rc frames designed according to different building codes. Eng. Struct. 2020, 216, 110397. [CrossRef]

24. EN 1991-1-1:2002. Eurocode 1: Actions on Structures; CEN: Brussels, Belgium, 2002.

25. Taerwe, L.; Matthys, S. Fib Model Code for Concrete Structures 2010; Ernst \& Sohn, Wiley: Berlin, Germany, 2013 ; pp. 1-402.

26. Verderame, G.M.; Stella, A.; Cosenza, E. Le proprietà meccaniche degli acciai impiegati nelle strutture in c.a. realizzate negli anni ‘60. In Proceedings of the Atti del X Congresso Nazionale ANIDIS 'L'ingegneria Sismica in Italia, Potenza, Matera, Italy, 9-13 September 2001.

27. Khahn, F.R. Tubular structures for tall buildings. In Handbook of Concrete Engineering; Fintel, M., Ed.; Van Nostrand Reinhold Company: New York, NY, USA, 1985; pp. 399-410.

28. Kwan, A.K.H. Simple method for approximate analysis of framed tube structures. J. Struct. Eng. 1994, 120, 1221-1239. [CrossRef]

29. Gaur, H.; Goliya, R.K. Mitigating shear lag in tall buildings. Int. J. Adv. Struct. Eng. 2015, 7, 269-279. [CrossRef] 